\title{
TECCIENCIA
}

\section{Simulation of the OFDM technique for the transmission of digital radio}

\section{Simulación de la técnica de modulación OFDM para propósitos de transmisión de radio digital}

\author{
Marcelo Herrera ${ }^{1}$, Miguel Pérez ${ }^{2}$ \\ ${ }^{1}$ Universidad de San Buenaventura, Bogotá, Colombia, mherrera@usbbog.edu.co \\ ${ }^{2}$ Universidad Distrital Francisco José de Caldas, Bogotá, Colombia, nperezp@ udistrital.edu.co
}

\begin{abstract}
The present project is motivated by the necessity of analyzing the technique of OFDM modulation and its performance, focused to the Transmission of Digital Radio. Traditionally all the radio programs are transmitted by FM, and AM modulations, and the radio should be tuned to each one of these frequencies; this used a wide range of the spectrum for a relatively short range of stations, limiting the experience of listening. In this project, a modulation system for Digital Radio Transmission is pretended, in order to combine multiple streams of audio in a relatively narrow frequency band, centered in a definite transmission frequency.
\end{abstract}

Keywords: OFDM modulation, Digital Radio, Spread Spectrum, Wireless Transmission.

\section{Resumen}

El presente proyecto está motivado por la necesidad de analizar la técnica de modulación OFDM y su desempeño enfocado en la transmisión de radio digital. Tradicionalmente los programas de radio fueron transmitidos a diferentes frecuencias vía FM y AM y la radio debía ser sintonizada a cada una de las frecuencias, de acuerdo a las necesidades, utiliza un amplio rango del espectro para una cantidad relativamente pequeña de estaciones, limitando la experiencia del escucha. En este proyecto se pretende desarrollar un sistema de modulación para la transmisión de radio digital que combinen múltiples flujos de audio en una banda relativamente angosta centrada en una frecuencia de transmisión

Palabras clave: Espectro ensanchado, Modulación OFDM, Radio digital, trasmisión inalámbrica.

\section{Introduction}

A radio digital transmission system is composed by the following processes:

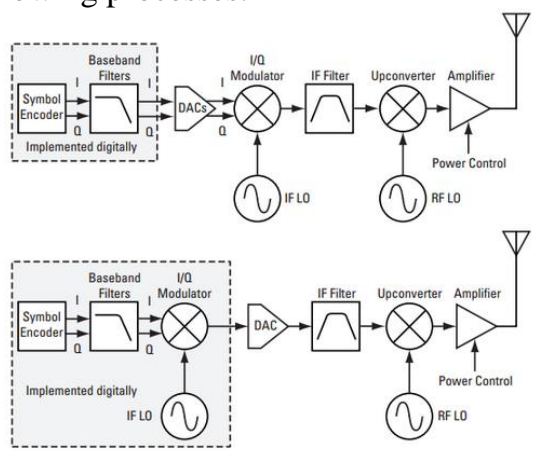

Figure 1. Digital radio general sketch [1]
This is the classic system of a radio transmission system. The objective of the present project is to simulate an OFDM modulation system, core of the Radio Digital system. The main purpose is to reduce the bandwidth of the signal, delivering lower costs for the total transmission system in total, maintaining the required quality. The research question for this investigation is the following: "Which are the advantages of radio digital transmission with OFDM, in comparison with the classic methods of transmission?"

The figure 1 resumes the classic implementation of a digital radio transmitter. The bit-flux (message) is 


\section{TECCIENCIA}

the input of the module of the symbol coding process, where the in-phase and the quadrature components are separated. After this, the binary flux is mapped to continuous modulated signals, ready for transmission. Finally, after the converters and the gain stage, the signal becomes ready to be transmitted.

This block diagram, is, nevertheless, a complex and low efficient implementation of the transmission algorithm.

It has been demonstrated by [2], that this type of modulation represents a remarkable improvement with respect to bandwidth, costs and codification. The implementation in this case is useful for radio digital transmission purposes.

\section{OFDM Modulation for Digital Radio}

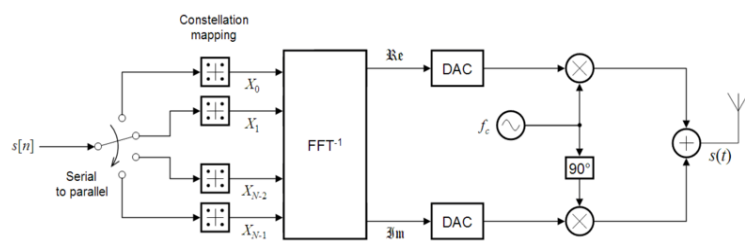

Figure 2. OFDM - Transmission System Transmitter Module [1]

OFDM (Orthogonal Frequency Division Multiplexing) modulation belongs to the type of modulations called Multi-Carrier Modulation (MCM). These modulations can be interpreted as a series of neighboring modulations in distinct subcarrier frequencies and excited by a single symbol data vector. The vector components $d n$, are used as data symbol in the different subcarrier. OFDM is a special case of MCM, because the signals of the different sub-carriers are mutually orthogonals. Though it can be not deduced from the denomination of OFDM, or from the orthogonality principle, in the different sub-carriers lineal modulation is used (ASK, PSK).

\section{Modulated signal in the continuous time domain}

The modulated signal is:

$$
s(t)=A_{s} \sum_{n} d_{n}^{T} h\left(t-n T_{s}\right)
$$

Data symbols in the different vector components $d_{n}=\left[d_{n, 0}, \ldots, d_{n, N_{q}-1}\right]^{T}$ can be arbitrary chosen. Frequently in all the components, the same set is chosen and the constellation can be, for example, QAM, PSK, APSK. The definition of the complete correspondent constellation is added to the OFDM denomination, for example OFDM-8PSK. If $M_{d}^{\prime}$ is designed as the number of data symbols of a data vector component and $d_{n, i} \in\left\{d^{(i)}\right\}_{i=0}^{M_{d}}$, then the total number of data symbols $\mathbf{d}_{\mathbf{n}}$ is $M_{d}=\left(M_{d}^{\prime}\right)^{N_{q}}$ The modulation impulse is:

$$
\mathrm{h}(\mathrm{t})=\left[\begin{array}{c}
1 \\
e^{j 2 \pi \Delta f t} \\
\cdot \\
e^{j 2 \pi\left(N_{q}-1\right) \Delta f t}
\end{array}\right] v_{r e c 1}(t)
$$

where the impulse $v_{\text {rec } 1}(t)$ is an impulse of the REC1 type.

$$
v_{r e c 1}(t)=\frac{1}{\sqrt{T_{s}}}\left(U(t)-U\left(t-T_{s}\right)\right)
$$

The individual components of the modulation impulse vector are generated with the REC1 impulse in the multiples of the frequency $\Delta f$. The respective frequency $i \Delta f$ is defined as the sub-carrier signal. The components

$$
h_{i}(t)=e^{j 2 \pi i \Delta f t} v_{\text {rec } 1}(t), i \in\left\{0, \ldots,\left(N_{q}-1\right)\right\}
$$

Generate an orthogonal system, if and only if,

$$
\Delta f=\frac{1}{T_{s}}
$$

\section{Modulated signal in discrete time}

A great advantage of the OFDM modulation is the possibility to use the FFT algorithm for the generation of samples of the modulated signal in discrete time. In the next lines, the expressions for the modulated signal in discrete time are deduced.

The expression for the modulated signal, replacing the modulation impulse and performing vector multiplication is,

$$
\begin{gathered}
s(t)=A_{s} \sum_{n} \sum_{i=0}^{N_{q}-1} d_{n, i} e^{j 2 \pi i \Delta f\left(t-n T_{s}\right)} v_{r e c 1}\left(t-n T_{s}\right)= \\
A_{s} \sum_{n} \sum_{i=0}^{N_{q}-1} d_{n, i} e^{j \pi_{s} i t} v_{r e c 1}\left(t-n T_{s}\right)
\end{gathered}
$$

Where the orthogonality condition $\Delta f T_{s}=1$ is used. The expression

$$
q\left(d_{n}, t\right)=\sum_{i=0}^{N_{q}-1} d_{n, i} e^{j \frac{2 \pi}{T_{s}} i t}
$$

Is periodic with period $\mathrm{Ts}$ and it has components in the discrete frequencies $i \Delta f=i / T_{s}, i \in\left\{0, \ldots,\left(N_{q}-1\right)\right\}$. For the modulated signal, then,

$$
s(t)=A_{s} \sum_{n} q\left(d_{n}, t\right) v_{\text {rec } 1}\left(t-n T_{s}\right)
$$

The signal $q\left(d_{n}, t\right)$ has a spectrum that consists on delta-direc functions in the Nq-carriers.

$$
F\left[q\left(d_{n}, t\right)\right]=\sum_{i=0}^{N_{q}-1} d_{n, i} \delta(f-i \Delta f)
$$




\section{TECCIENCIA}

The bandwidth of the signal $q\left(d_{n}, t\right)$ is $B_{q}=\left(N_{q}-1\right) \Delta f$. This signal can be defined in the discrete time with Fp (sampling frequency).

$$
f_{p}=N_{q} \Delta f=\frac{N_{q}}{T_{s}}
$$

The sampling period is $T_{p}=1 / f_{p}$

The samples of the signal are $q\left(d_{n}, k T_{p}\right)$.The situation is depicted in

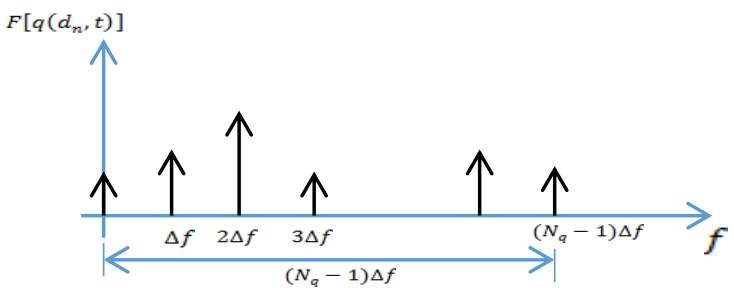

Figure 3. OFDM symbol channel spectrum [1]

For the samples $q\left(d_{n}, k T_{p}\right)$

$$
\begin{gathered}
q\left(d_{n}, k T_{p}\right)=\sum_{i=0}^{N_{q}-1} d_{n, i} e^{j \frac{2 \pi}{T_{s}} i k T_{p}}= \\
\sum_{i=0}^{N_{q}-1} d_{n, i} e^{j \frac{2 \pi}{N_{q}} i k}=N_{q} D F T^{-1(k)}\left[\left\{d_{n, i}\right\}_{i=0}^{N_{q}}\right.
\end{gathered}
$$

For the generation of the samples it is enough to perform the inverse DFT of the data symbols. For the DFT calculation, the FFT implementation is performed.

Unfortunately, a similar method is not possible to perform for the entire modulated signal $\mathrm{s}(\mathrm{t})$. This is due to the presence of the impulse $v_{\text {rec } 1}(t)$, which spectrum is,

$$
F\left[v_{\text {rec } 1}(t)\right]=\sqrt{T_{s}} e^{-j 2 \pi f T_{s} / 2} \operatorname{sinc}\left(T_{s} f\right)
$$

With infinite bandwidth. In the discrete time domain, it is possible to perform the generation of $q\left(d_{n}, k T_{p}\right)$ and the generation of these samples, and then $q\left(d_{n}, t\right)$

$$
q\left(d_{n}, t\right)=\sum_{k} q\left(d_{n}, k T_{p}\right) \operatorname{sinc}\left(\frac{t-k T_{p}}{T_{p}}\right)
$$

The multiplication by the signal $v_{\text {rec } 1}\left(t-n T_{s}\right)$ and after this, the summation must be realized in the continuous time domain. The multiplication by the rectangular signal $v_{\text {rec } 1}\left(t-n T_{s}\right)$ and then the sum, corresponds with the commutation of the signal $q\left(d_{n}, t\right)$ at the output, always for the interval $t \in$ $\left[n T_{s},(n+1) T_{s}\right]$. The situation is depicted in the following figure.

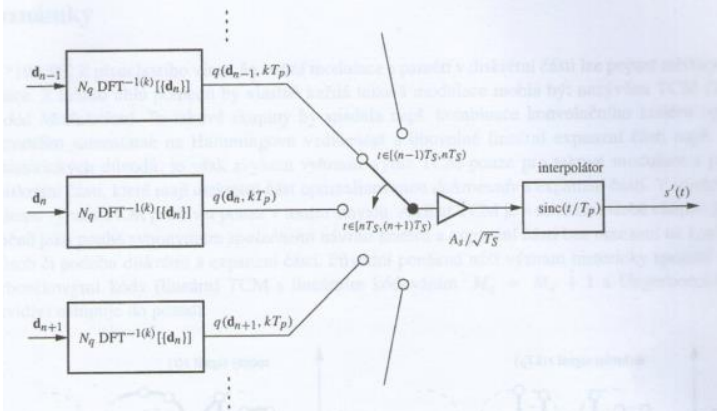

Figure 4. OFDM Modulation in discrete time [1]

\section{Modulated signal in discrete time- Approximation}

If the number of subcarriers $N_{q}$ is huge, the OFDM signal approximation can be generated in discrete time. The higher the number of $N_{q}$, the lower will be the value of the error of the power due to approximation. The idea behind the approximation is based on signal commutation, before the interpolator. In this way, the modulator will have only one interpolator in common and all the operations will develop in discrete time. In this way, the sampling theorem is broken, cause the signal $s(t)$ cannot correctly be sampled with the sampling frequency $f_{p}$.

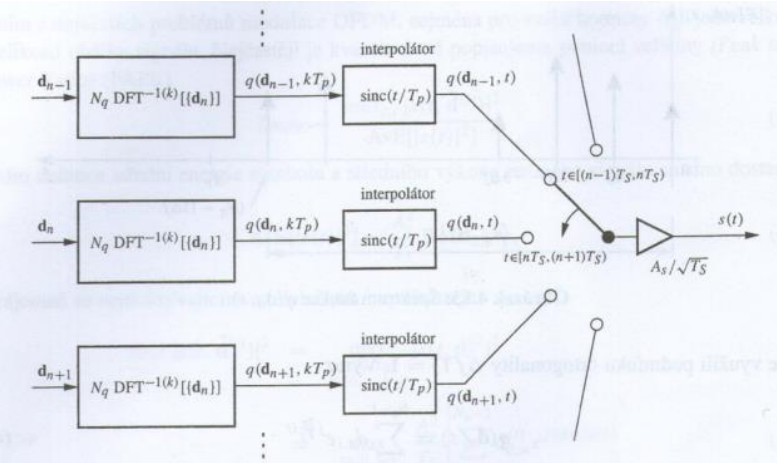

Figure 5. OFDM Modulation Implementation Approximation [1]

The samples of the modulated signal are obtained with $\mathrm{t}=k T_{p}$.

$$
s\left(k T_{p}\right)=A_{s} \sum_{n} q\left(d_{n}, k T_{p}\right) v_{r e c 1}\left(k T_{p}-n N_{q} T_{p}\right)
$$

Where $q\left(d_{n}, k T_{p}\right)$ is periodic at the variable $\mathrm{k}$ with period $N_{q}$. Nevertheless, the samples $s\left(k T_{p}\right)$ are obtained without respecting the sampling theorem, and therefore the interpolated signal

$$
s^{\prime}(t)=A_{s} \sum_{k} k T_{p} \operatorname{sinc}\left(\frac{t-k T_{p}}{T_{p}}\right)
$$




\section{TECCIENCIA}

Is not equal to the real modulated signal, but an approximation.

\section{OFDM system simulation in MATLAB}

Further, the code in MATLAB $2012 a$ is presented for the simulation of OFDM Modulation.

The command for reading the wav-signal and represent it in quantization levels according to the number of bits (16), is:

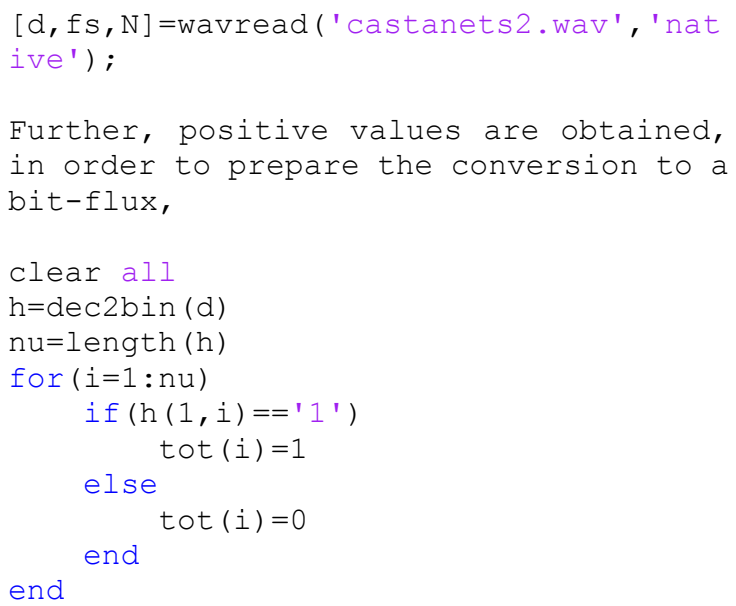

\section{Results}

The generated signal is a discrete sequence, depicted in the following figure. It is a discretization of an analogue signal, which in the real world can correspond to an audio-broadcasting time-varying signal, discretized with a 16-bit depth resolution at $44.1 \mathrm{kHz}$ sampling frequency.

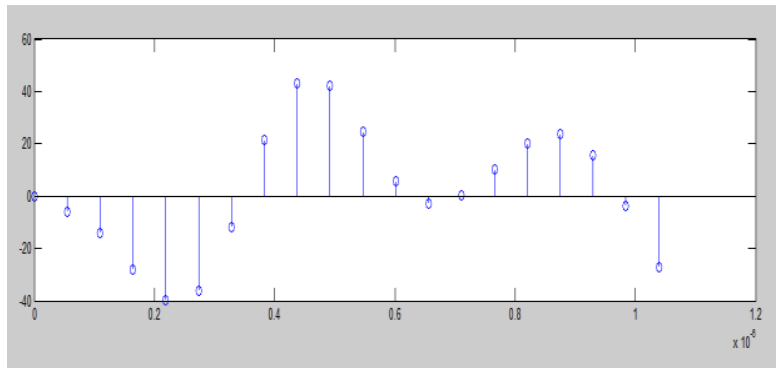

Figure 6. Generated signal

The Power Spectral Density (PSD) of the original sequence is depicted in the following figure. It is a more refined representation of the frequency representation of the signal.

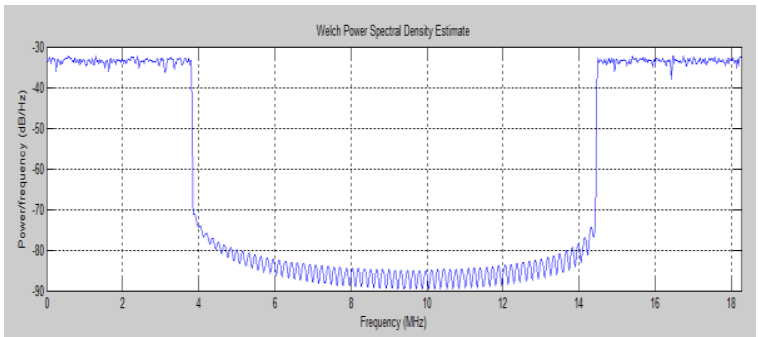

Figure 7. Power Spectral Density (PSD) of the original sequence

The resultant spectrum of the simulation, is depicted in figure 8, which is in accordance to theory [1]. It is, as shown, a spectrum which enables to minimize ISI (inter-symbol interference) in comparison to other analogue or even digital systems of modulation and transmission.

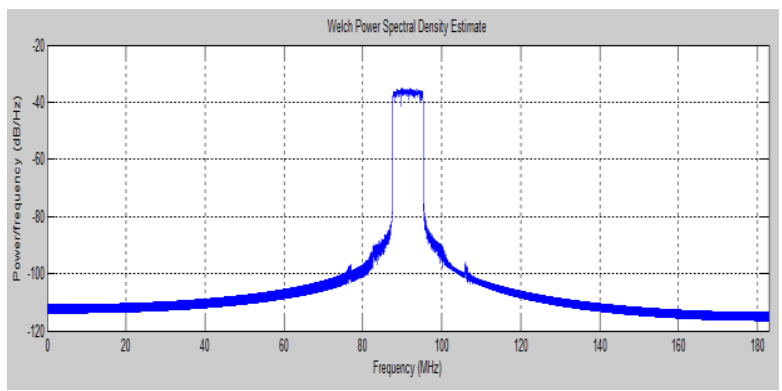

Figure 8. Signal spectrum OFDM

\section{Conclusions}

An OFDM system simulation has been performed. The OFDM modulation system has been simulated 


\section{TECCIENCLA}

in MATLAB 2012a, obtaining a spectrum in accordance to the theory. The designed modulation system represents a possibility for the digital radio transmission

\section{References}

[1] J. Sykora, Teorie Digitální Komunikace, Praha: Skripta, 2002.

[2] M. Wouters, G. Vanwijnsberghe, P. Van Wesemael, T. Huybrechts and S. Thoen Imec, "Real time implementation on FPGA of an OFDM based wireless LAN modem extended with adaptive loading," in Proceedings of the 28th European, Belgica, 2002. 